\title{
Assessment of Oral Health-Related Photographs by Dentists and Professional Non-Dental Caregivers - A Quantitative Comparative Study
}

Stefanie Krausch-Hofmann ( $\sim$ stefanie.krauschhofmann@kuleuven.be)

Katholieke Universiteit Leuven https://orcid.org/0000-0003-4427-5025

Trung Dung Tran

Katholieke Universiteit Leuven

Dominique Declerck

Katholieke Universiteit Leuven

Johanna de Almeida Mello

Katholieke Universiteit Leuven

Anja Declercq

Katholieke Universiteit Leuven

Emmanuel Lesaffre

Katholieke Universiteit Leuven

Jan De Lepeleire

Katholieke Universiteit Leuven

Joke Duyck

Katholieke Universiteit Leuven

\section{Research article}

Keywords: Oral Health Assessment, Oral Photographs, Caregivers, Dentists

Posted Date: November 19th, 2019

DOI: https://doi.org/10.21203/rs.2.17424/v1

License: (1) (1) This work is licensed under a Creative Commons Attribution 4.0 International License. Read Full License 


\section{Abstract}

Background Photographs might aid professional non-dental caregivers to detect problems when inspecting the mouth of care-dependent older individuals. This study evaluated whether the assessment of oral health-related conditions presented on photographs systematically differed between dentists and professional non-dental caregivers.

Methods Photographs were taken from long-term care facility residents and from patients at the Department of Dentistry of a University Hospital. The following oral health aspects were depicted: denture hygiene, oral hygiene, teeth, gums, tongue and palate/lips/cheeks. Collection continued until a pool of 2035 photographs was available for each oral health aspect, including a variety of conditions from perfect health and hygiene to severe problems. The total pool consisted of 179 photographs. A segmented Visual Analogue Scale was applied to assess the conditions presented on the photographs. The benchmark was established by three dentists with academic-clinical expertise in gerodontology, special needs dentistry and periodontology. For each photograph they provided a collective score after reaching consensus. Photographs were assessed individually by 32 general dentists and by 164 professional non-dental caregivers. Linear mixed effects models and generalized linear mixed effects models were fitted and mean squared errors were computed to quantify differences between both groups related to the benchmark.

Results For the different oral health aspects, absolute distances from the benchmark scores were 1.13 (95\% Cl:1.03-1.23) to 1.51 (95\% Cl:1.39-1.65) times higher for the caregivers than for the dentists. The odds to overestimate the condition were higher for the caregivers than the dentists for oral hygiene $(\mathrm{OR}=0.72,95 \% \mathrm{Cl}=0.62-0.84)$ and teeth $(\mathrm{OR}=0.74 ; 95 \% \mathrm{Cl}=0.61-0.88)$. The odds to underestimate the condition were higher for the caregivers than the dentists for gums (OR=1.39;95\%Cl:1.22-1.59) and palate/lips/cheeks $(\mathrm{OR}=1.22 ; 95 \% \mathrm{Cl}=1.07-1.40)$. Over all assessments, the variance in caregiver scores was $1.9(95 \% \mathrm{Cl}: 1.62-2.23)$ times higher than that for the dentists.

Conclusion Small but significant systematic differences were found between dentists and non-dental caregivers regarding the assessment of oral health-related conditions presented on clinical photographs. When photographs are used to aid non-dental caregivers with the oral health assessment, these visualizations should be complemented with comments to facilitate accurate interpretation.

\section{Background}

International research shows that oral health in care-dependent individuals is poor (1-3). This is confirmed by the 'World Report on Ageing and Health', which states that "Oral health is a crucial but often neglected area of healthy ageing" (4). The challenges of oral disease are considerable due to associations with impaired oral functioning (5), aspects of general health (6-8), a number of systemic diseases (9-11) and quality of life (12-15). 
Daily oral care and regular professional check-ups are the cornerstones of good oral health. They both are impeded in care-dependent individuals due to physical and cognitive restraints and insufficient availability or accessibility of care (5). An oral health assessment by non-dental caregivers is suggested as a supplementary procedure to detect oral-health related care- and treatment needs (16). A variety of assessment instruments for caregivers are available such as the Oral Health Assessment Tool (OHAT), the Revised Oral Assessment Guide (ROAG) or the oral health-related section of the Minimum Data Set/interRAI Suite of Assessment Instruments (MDS/interRAI). The instruments above expect caregivers to assess different oral health aspects on a nominal scale, in order to determine whether assistance with daily oral care and/or referral to an oral health professional is required. However, studies on concurrent validity that compare professional oral examination data with non-dental caregiver registrations show shortcomings in the latter in correctly detecting oral care needs (16-19).

As pictures do support, reinforce and illustrate written text (20), clinical oral photographs could be used to visualize item categories and illustrate training materials. This may help non-dental caregivers to differentiate between acceptable and care-requiring oral conditions.

However, expertise differences with regard to the interpretation of medical visualizations have been described in literature (21). This raises the question of whether non-dental caregivers see what dentists see. Or, in other words, whether the interpretation of clinical photographs systematically differs between both groups.

To our knowledge the present study is the first to explore, to what extent the assessment of oral healthrelated conditions shown on clinical photographs differs between dentists and non-dental caregivers. Based on a Visual Analogue Scale, absolute distance, direction of the distance and variance of the assessments related to a benchmark are compared in this study.

\section{Methods}

\section{Background of the study}

The present study is part of a larger research project that aims to develop an optimized photographsupported oral health-related section for the interRAl suite of Assessment Instruments (ohr-interRAl). The interRAI suite is used internationally and consists of tools for comprehensive assessment of conditions and needs of care-dependent individuals. Different versions are available for various sectors, such as home care, nursing homes, hospitals or mental health care settings (22).

\section{Collection of photographs}

Photographs were taken from consenting long-term care facility residents and from patients at the Department of Dentistry of a University Hospital. Equipment for professional digital dental photography was used: Canon EOS5500 camera, EF-S60mmF2.8USM Macro Objective Lens and a Macro Ring Lite MR-14EX. Lip and cheek retractors as well as oral mirrors were used. 
Photographs were taken of the following oral health aspects: denture hygiene, oral hygiene, teeth, gums, tongue and palate/lips/cheeks. Collection continued until a pool of 20-35 photographs was available for each oral health aspect including a variety of conditions from perfect health and hygiene to severe problems. The pool consisted of 179 clinical photographs.

\section{Assessment of the photographs and participants}

Photographs were presented in six blocks in randomized order on an individual PC screen that was placed in front of each participant. A three-segmented 150mm Visual Analogue Scale (VAS), (100mm two-segmented for teeth) was used for the assessment. Participants were instructed to apply the VAS as follows: 1. First select a segment of the scale. The definition of the segment should most suitably describe the appearance of denture or tissue shown on the photograph (Table 1). 2. Then indicate a position on the VAS that is located within the range of the chosen segment. Zero on the VAS represents a perfectly healthy or clean condition, while the right end of the scale indicates severe problems. An example of a photograph on denture hygiene and of the scale that was applied is shown in Figure 1 (Figure 1: Example of a photograph on denture hygiene and of the scale that was applied). Participants did not receive further training related to appearance, diagnosis or interpretation of oral health-related pathology.

The benchmark was established by three dentists affiliated with the Dentistry Department of the University Hospitals with expertise in gerodontology, special needs dentistry and periodontology. For each photograph they provided a collective VAS score after reaching consensus. Each photograph was assessed individually by 32 dentists (spread over 2 sessions) and by 164 non-dental caregivers (spread over six sessions). The sessions were organized during certified continuous education activities on the relationship between oral health and general health.

To recruit participants, an invitation was sent to a all dentists who had attended previous permanent education activities organized by the Department of Oral Health Sciences of the University. Care facilities, home care providers, high-schools for nursing education, umbrella organizations and professional associations for caregivers in Flanders, Belgium were contacted to circulate the invitation among employees or members. Professional non-dental caregivers working with clients in home- or long-term care were addressed, such as nurses, auxiliary nurses, speech therapists, occupational therapists, dietitians or physicians.

\section{Table 1: Verbal description of the segments of the Visual Analogue Scale}




\begin{tabular}{|c|c|c|c|}
\hline & 1 Acceptable & $\begin{array}{l}2 \text { Not acceptable, } \\
\text { moderate }\end{array}$ & $\begin{array}{l}3 \text { Not acceptable, } \\
\text { marked }\end{array}$ \\
\hline $\begin{array}{l}\text { Denture hygiene: Part of the oral } \\
\text { surface covered with dental } \\
\text { plaque or tartar }\end{array}$ & $<1 / 3$ & $1 / 3-2 / 3$ & $>2 / 3$ \\
\hline $\begin{array}{l}\text { Oral hygiene: Part of the surface } \\
\text { of teeth or denture retainers } \\
\text { covered with dental plaque or } \\
\text { tartar }\end{array}$ & $<1 / 3$ & $1 / 3-2 / 3$ & $>2 / 3$ \\
\hline Teeth & $\begin{array}{l}\text { All teeth sound, } \\
\text { adequately filled, } \\
\text { maybe tooth wear }\end{array}$ & $\begin{array}{l}\geq 1 \text { tooth broken, } \\
\text { with decay, defect } \\
\text { fillings, root } \\
\text { remnants }\end{array}$ & \\
\hline Gums & $\begin{array}{l}\text { Pink and firm, } \\
\text { maybe minor } \\
\text { aberration in color } \\
\text { or texture }\end{array}$ & $\begin{array}{l}\text { Moderate redness, } \\
\text { swelling, glassy }\end{array}$ & $\begin{array}{l}\text { Marked redness, } \\
\text { swelling, bleeding, } \\
\text { sores, wounds, } \\
\text { fistulas }\end{array}$ \\
\hline Tongue & $\begin{array}{l}\text { Small bumps on } \\
\text { upper and lateral } \\
\text { surface, moist, } \\
\text { pink }\end{array}$ & $\begin{array}{l}\text { General redness, } \\
\text { patches, extensive } \\
\text { coating, deep } \\
\text { grooves, dry }\end{array}$ & $\begin{array}{l}\text { Red and/or white } \\
\text { lesions, swelling, } \\
\text { sores, wounds }\end{array}$ \\
\hline $\begin{array}{l}\text { Palate, oral surface of lips and } \\
\text { cheeks }\end{array}$ & $\begin{array}{l}\text { Smooth, moist, } \\
\text { pink }\end{array}$ & $\begin{array}{l}\text { General redness, } \\
\text { rough, dry }\end{array}$ & $\begin{array}{l}\text { Red and/or white } \\
\text { lesions, swelling, } \\
\text { sores, wounds }\end{array}$ \\
\hline
\end{tabular}

Verbal description of the appearance of dentures or oral tissues for each segment of the Visual Analogue Scale that was applied for assessment of the photographs.

\section{Statistical analysis}

The absolute value of the distance from the benchmark score was calculated for dentists and for nondental caregivers for each photograph. Due to skewness of the distribution, logarithm of the values was used. The direction of distance from the benchmark indicated whether the score assigned to a photograph was lower, equal or higher than the benchmark score.

To quantify differences between caregivers and dentists with regard to the distance from the benchmark as well as the direction of this difference, a linear mixed effects model and a generalized linear mixed effects model were fitted, respectively. Type of assessor (caregiver, dentist) and oral health aspect (denture hygiene, oral hygiene, teeth, gums, tongue, palate/lips/cheeks) were added to the models as random effects. 
Mean squared errors were computed to compare the scores provided by non-dental caregivers and dentists with regard to the variance around the benchmark for each oral health aspect. Statistical programs R (version 3.6) and SAS (version 9.4) were used.

\section{Results}

\section{Characteristics of dentists and caregivers}

Table 2 shows that more women than men participated in the study. In the caregiver group the gender imbalance was more pronounced with $94.5 \%$ female participants. The caregiver group was also relatively younger than the dentist group. Most frequent occupations among caregivers were nurses and nurse aids with $57.9 \%$ and $23.8 \%$, respectively. All dentists were primary dental care providers with $46.9 \%$ having an additional training in endodontology or prosthetic dentistry.

Table 2: Characteristics of dentists and non-dental caregivers

\begin{tabular}{llll} 
& & \multicolumn{1}{c}{$\begin{array}{c}\text { Dentists, } \\
\mathrm{N}=32\end{array}$} & $\begin{array}{l}\text { Caregivers, } \\
\mathrm{N}=164\end{array}$ \\
\hline \multirow{2}{*}{ Gender in \% } & Female & 68.8 & 94.5 \\
\cline { 2 - 4 } & Male & 31.2 & 5.5 \\
\hline $\begin{array}{l}\text { Age groups in } \\
\%\end{array}$ & $<30$ years & & \\
\cline { 2 - 4 } & $30-40$ years & 9.4 & 29.3 \\
\cline { 2 - 4 } & $41-50$ years & 12.5 & 22.6 \\
\cline { 2 - 4 } & $>50$ years & 31.3 & 37.8 \\
\hline
\end{tabular}

Occupation

Nurse

Nurse aid

Nurse lecturer

Speech therapist

Others (e.g., physician, psychologist, dietitian)
57.9

23.8

7.3

3.7

7.3

\section{Distance from the benchmark}

Figure 2 (Figure 2: Density plots to illustrate distances from the benchmark scores for dentists and caregivers) illustrates the distance from the benchmark for dentists and caregivers, for each oral health 
aspect, respectively. In both groups, the majority of the assessments peak around the value zero, indicating no or little distance from the benchmark. However, in each of the six graphs, the curve of the dentists exceeds the curve of the caregivers around the zero value. This implies that the distance from the benchmark tends to be lower for dentists. Accordingly, over all photographs the mean absolute distance from the benchmark score on the VAS is 20.1 for the dentists and 27.7 for the caregivers.

Table 3 presents the results of the linear mixed effects model. It confirms that for all oral health aspects the distances from the benchmark scores are 1.13-1.51 times higher for the caregivers than for the dentists.

\section{Table 3: Distance from the benchmark}

\begin{tabular}{llll}
$\begin{array}{l}\text { Oral } \\
\text { health } \\
\text { aspect }\end{array}$ & $\begin{array}{l}\text { Distance from the benchmark: difference between dentists } \\
\text { and caregivers on log scale (increase for caregivers) }\end{array}$ & $\begin{array}{l}95 \% \\
\text { confidence } \\
\text { interval }\end{array}$ & $\begin{array}{l}\text { P- } \\
\text { value }\end{array}$ \\
\hline $\begin{array}{l}\text { Denture } \\
\text { hygiene }\end{array}$ & $0.118(1.13)$ & $\begin{array}{l}0.028- \\
0.208\end{array}$ & 0.010 \\
\hline $\begin{array}{l}\text { Oral } \\
\text { hygiene }\end{array}$ & $0.326(1.39)$ & $0.236-$ & $<.0001$ \\
\hline Teeth & $0.411(1.51)$ & 0.416 & \\
\hline Gums & $0.414(1.51)$ & $0.308-$ & $<.0001$ \\
\hline $\begin{array}{l}\text { Tongue } \\
\text { nalate, }\end{array}$ & $0.368(1.44)$ & 0.513 & \\
\hline $\begin{array}{l}\text { Paps, } \\
\text { cheeks }\end{array}$ & $0.347(1.41)$ & $0.328-$ & $<.0001$ \\
\hline & & 0.499 & $<.0001$ \\
\hline
\end{tabular}

For all oral health aspects the distances from the benchmark scores were significantly higher for the caregivers than for the dentists.

\section{Direction of the distance from the benchmark}

With regard to the direction of the distance, a lower VAS score than the benchmark implies that the condition was underestimated by the participant. A higher score than the benchmark implies that the condition was overestimated. Table 4 provides an overview over all photographs for caregivers and dentists.

Table 4: Direction of the distance from the benchmark - overview over all photographs 
Direction of the distance from the benchmark

Lower score than benchmark (= underestimation of the condition)

Same score as benchmark

Higher score than benchmark (= overestimation of the condition)
Dentists in \%

40.62

3.37

56.02
Caregivers in \%

41.87

0.78

57.35

The results of the generalized linear mixed effects model allow a more detailed view. Table 5 illustrates the odds ratios for caregivers versus dentists to assign a lower score than the benchmark. Odds ratios are $<1$ for aspects of hygiene and teeth, but $>1$ for aspects of the oral soft tissues. This implies that compared to the dentists, caregivers tended to overestimate aspects of hygiene and condition of the teeth, but underestimated aspects of the soft tissues.

\section{Table 5: Direction of the distance from the benchmark}

\begin{tabular}{llll} 
& $\begin{array}{l}\text { Underestimation of the condition } \\
\text { (lower score than benchmark, }\end{array}$ & $95 \%$ confidence interval & P-value \\
& odds ratio caregivers/dentists) & & \\
\hline Denture hygiene & 0.95 & $0.81-1.11$ & 0.522 \\
\hline Oral hygiene & 0.72 & $0.62-0.84$ & $<.0001$ \\
\hline Teeth & 0.74 & $0.61-0.88$ & 0.001 \\
\hline Gums & 1.39 & $1.22-1.59$ & $<.0001$ \\
\hline Tongue & 1.12 & $0.97-1.30$ & 0.118 \\
\hline Palate/lips/cheeks & 1.22 & $1.07-1.40$ & 0.004
\end{tabular}

For oral hygiene and teeth the odds to assign a lower score than the benchmark were significantly higher for the dentists. For gums and palate/lips/cheeks the odds to assign a lower score than the benchmark were significantly higher for the caregivers.

\section{Variance around the benchmark}

Considering all oral health aspects, the variance around the benchmark scores was significantly higher for the caregivers than for the dentists. The mean squared error was 1.9 times higher for the caregivers than for the dentists ( $95 \%$ confidence interval: 1.62-2.23). When mean squared errors were computed for each oral health aspect separately, no differences were found between the two groups. 


\section{Discussion}

To our knowledge this is the first study that evaluated whether the assessment of oral health-related conditions presented on clinical photographs systematically differed between dentists and non-dental caregivers. Although participants were not selected randomly, results indicate

\section{small but systematic differences.}

A first graphical analysis illustrated that in both groups the majority of the assessments peaked around the benchmark scores. Graphs of dentists and caregivers appeared approximately congruent. This is in line with two studies from the field of dermatology showing high accuracy of nurses to classify skin damage on photographs when compared to dermatologists $(23,24)$.

A more detailed evaluation of the data revealed small but systematic differences between both groups, with caregivers having a significantly higher distance from the benchmark than dentists. In addition, the variance in scores provided by the caregivers was significantly higher than the variance in scores provided by the dentists. This confirms the findings published by Yazdanyar et al. (2013) who compared general practitioners and dermatologists regarding their congruence with a benchmark in identifying acne morphology using photographs and a short description. In all cases, responses of the dermatologists were more congruent with the benchmark and variation was lower compared to the general practitioners (25). Accordingly, a meta-analysis on differences in the comprehension of visualizations found higher performance accuracy and shorter reaction times for experts than non-experts (26).

With regard to the direction of the distance from the benchmark, differences between dentists and caregivers depended on the type of oral health aspect. For photographs showing aspects of oral hygiene and teeth, caregivers tended to overestimate the condition compared to dentists. In contrast, for photographs showing gums and palate/lips/cheeks the odds to underestimate the condition were higher for the caregivers than for the dentists. To suggest a possible explanation, age-related physiological changes such as discoloration or tooth wear might be misinterpreted by caregivers. Furthermore, dental plaque and tooth decay may look impressive to non-dental caregivers, while dentists know that these conditions often can be treated easily. On the other hand, caregivers are maybe less aware than dentists that oral soft tissue lesions can involve harmful malignities.

Gegenfurtner et al. (2013) provide an overview of the underlying theories on how expertise is related to differences in comprehension of medical visualizations. The modified neural efficiency theory suggests that in experts only those cortical areas are activated that are relevant for diagnostic decision making. Consistent evidence further shows that medical experts need less time than novices to detect abnormalities. This is caused by an extended visual span that allows a global analysis of the visual material (21).

A review on the role of pictures in improving health communication concluded that visualizations can support comprehension by providing a context for organizing text information. Pictures are particularly 
helpful when content is complex and when prior knowledge of individuals is low. However, for complex pictures instruction and guidance is needed to ensure a correct interpretation (27). Hence, when photographs are used to aid non-dental caregivers with the oral health assessment, these visualizations should be complemented with comments to facilitate accurate interpretation. Results of the current study indicate that for aspects of hygiene and teeth, instructions are needed to differentiate between pathology and normal, age-related phenomena. Comments should further emphasize that soft tissues require close attention.

With regard to the development of the optimized interRAl oral health-related section, the benefits of including visualizations might reach beyond the correct identification of care needs. Focus group discussions with caregivers revealed that oral health has low priority in the care environment and that the oral health-related section of the interRAl is completed only superficially without inspection of the mouth (28). As human beings are attracted to visual stimuli (20), photographs have the potential to enhance attention and raise awareness for the oral health assessment. By including various dimensions of oral health aspects, such as the dorsal, lateral and ventral aspect of the tongue, photographs might motivate a more thorough assessment of the mouth.

It needs to be mentioned that current training programs for non-dental caregivers include only few hours on oral health. A study showed that of 114 high schools in Norway providing basic education for auxiliary nurses, solely $49.1 \%$ offered three or more hours of teaching on oral health care (29). Of the 99 caregivers who participated in a French study, only $21 \%$ reported previous theoretical training with regard to oral disorders (30). More emphasis on the topic of oral health during the professional training of non-dental caregivers might raise awareness and the ability to correctly recognize pathology.

\section{Conclusions}

Small but significant systematic differences were found between dentists and non-dental caregivers regarding the assessment of oral health-related conditions presented on clinical photographs. When photographs are used to aid non-dental caregivers with the oral health assessment, these visualizations should be complemented with comments to facilitate accurate interpretation.

\section{Abbreviations}

- OHAT: Oral Health Assessment Tool

- ROAG: Revised Oral Assessment Guide

- MDS/interRAI: Minimum Data Set/interRAI Suite of Assessment Instruments

- ohr-interRAl: oral health-related section of the interRAI Suite of Assessment Instruments

- VAS: Visual Analogue Scale

\section{Declarations}




\section{Ethics approval and consent to participate}

The study was approved by the 'Ethics Committee Research UZ/KU Leuven' that evaluates medical and health related research at the KU Leuven University and the associated University Hospitals (study number s59152). Participants were informed comprehensively and provided written consent.

\section{Consent for publication}

Not applicable.

\section{Availability of data and materials}

All data analysed during this study are included in this published article [and its supplementary information files].

\section{Competing interests}

The authors declare that they have no competing interests.

\section{Funding}

This study was part of a research project financed by an internal fund of the KU Leuven (C24/15/034). Study design, analysis, interpretation and presentation of results was not influenced by the funding source.

\section{Authors' contributions}

All authors meet the criteria for authorship and all those entitled to authorship are listed as authors. SKH, $D D, J d A M, A D$ and JD designed the study and ensured approval of the Ethical Commitee. SKH and JdAM collected the clinical photographs and recruited participants for the assessment sessions. The assessment sessions were organized by SKH. TDT and EL analyzed the data and the results were discussed and interpreted in a meeting with all authors. SKH, TDT and JDL were major contributors in writing the manuscript.

\section{Acknowledgements}

The authors want to thank all the subjects who participated in this study. Without their cooperation, data collection would not have been possible.

\section{References}

1. De Visschere L, Janssens B, Reu G, Duyck J, Vanobbergen J. An oral health survey of vulnerable older people in Belgium. Clin Oral Investig. 2016;20:1903-1912. 
2. Chen $X$, Clark JJJ, Naorungroj S. Oral health in nursing home residents with different cognitive statuses. Gerodontology. 2013;30(1):49-60.

3. Panchbhai A. Oral health care needs in the dependant elderly in India. Indian J Palliat Care. 2012;18(1):19.

4. World Health Organization. World report on Ageing And Health. 2015. https://www.who.int/ (Accessed March 20, 2019)

5. Kossioni AE, Hajto-Bryk J, Maggi S, McKenna G, Petrovic M, Roller-Wirnberger RE, et al. An Expert Opinion from the European College of Gerodontology and the European Geriatric Medicine Society: European Policy Recommendations on Oral Health in Older Adults. J Am Geriatr Soc. 2017;66(3):609613.

6. Moriya S, Tei K, Nagatsu I, Muramatsu M, Inoue N, Miura H. Perceived chewing ability and need for long-term care in the elderly: a 5-year follow-up study. J Oral Rehabil [Internet]. 2012;39(8):568-575.

7. Moriya S, Notani K, Miura H, Inoue N. Relationship between masticatory ability and physical performance in community-dwelling edentulous older adults wearing complete dentures. Gerodontology. 2014;31(4):251-259.

8. Teixeira FB, Pereira Fernandes LDM, Noronha PAT, dos Santos MAR, Gomes-Leal W, Ferraz Maia CDS, et al. Masticatory deficiency as a risk factor for cognitive dysfunction. Int J Med Sci. 2014;11(2):209-214.

9. Graziani F, Gennai S, Solini A, Petrini M. A systematic review and meta-analysis of epidemiologic observational evidence on the effect of periodontitis on diabetes An update of the EFP-AAP review. $J$ Clin Periodontol. 2018 Feb;45(2):167-187.

10. Dietrich T, Webb I, Stenhouse L, Pattni A, Ready D, Wanyonyi KL, et al. Evidence summary: The relationship between oral and cardiovascular disease. Br Dent J. 2017;222(5):381-385.

11. Teeuw WJ, Slot DE, Susanto H, Gerdes VE a, Abbas F, D'Aiuto F, et al. Treatment of periodontitis improves the atherosclerotic profile: a systematic review and meta-analysis. J Clin Periodontol. 2014;41(1):70-79.

12. Kimura $Y$, Wada $T$, Ishine $M$, Ishimoto $Y$, Kasahara $Y$, Hirosaki $M$, et al. Community-dwelling elderly with chewing difficulties are more disabled, depressed and have lower quality of life scores. Geriatr Gerontol Int. 2009;9(1):102-104.

13. Haag DG, Peres KG, Balasubramanian M, Brennan DS. Oral Conditions and Health-Related Quality of Life: A Systematic Review. J Dent Res. 2017 Jul;96(8):864-874.

14. Masood M, Newton T, Bakri NN, Khalid T, Masood Y. The relationship between oral health and oral health related quality of life among elderly people in United Kingdom. J Dent. 2017;56:78-83.

15. Rouxel P, Tsakos G, Chandola T, Watt RG. Oral Health-A Neglected Aspect of Subjective Well-Being in Later Life. J Gerontol B Psychol Sci Soc Sci. 2018;73(3):382-386.

16. Chalmers JM, King PL, Spencer a J, Wright F a C, Carter KD. The oral health assessment tool-validity and reliability. Aust Dent J. 2005;50(3):191-199. 
17. Ribeiro MTF, Ferreira RC, Vargas AMD, Ferreira e Ferreira E. Validity and reproducibility of the revised oral assessment guide applied by community health workers. Gerodontology. 2014 Jun;31(2):101110.

18. Nordenram G, Ljunggren G. Oral status, cognitive and functional capacity versus oral treatment need in nursing home residents: a comparison between assessments by dental and ward staff. Oral Dis. 2002 Nov;8(6):296-302.

19. Hoben M, Poss JW, Norton PG, Estabrooks CA. Oral/dental items in the resident assessment instrument - minimum Data Set 2.0 lack validity: results of a retrospective, longitudinal validation study. Popul Health Metr. 2016;14(1):36.

20. Arbuckle K. The language of pictures: Visual literacy and print materials for Adult Basic Education and Training (ABET) The language of pictures: Visual literacy and print materials for Adult Basic Education and Training (ABET). Lang Matters. 2004;35(2):445-458.

21. Gegenfurtner A, Siewiorek A, Lehtinen E, Säljö R. Assessing the Quality of Expertise Differences in the Comprehension of Medical Visualizations. Vocat Learn. 2013;6(1):37-54.

22. InterRAI Instruments. http://www.interrai.org/instruments/ (Accessed March 20, 2019)

23. Russell Localio A, Margolis DJ, Kagan SH, Lowe RA, Kinosian B, Abbuhl S, et al. Use of photographs for the identification of pressure ulcers in elderly hospitalized patients: Validity and reliability. Wound Repair Regen. 2006;14(4):506-513.

24. Bliss DZ, Gurvich O V, Hurlow J, Cefalu JE, Gannon A, Wilhems A, et al. Evaluation of Validity and Reliability of a Revised Incontinence-Associated Skin Damage Severity Instrument (IASD.D.2) by 3 Groups of Nursing Staff. J Wound Ostomy Continence Nurs. 2018;45(5):449-455.

25. Yazdanyar S, Bryld LE, Heidenheim M, Jemec GBE. Do generalists and specialists agree on descriptive acne morphology? J Eur Acad Dermatology Venereol. 2013;27(1):116-120.

26. Gegenfurtner A, Lehtinen E, Säljö R. Expertise Differences in the Comprehension of Visualizations: A Meta-Analysis of Eye-Tracking Research in Professional Domains. Educ Psychol Rev. 2011;23(4):523-552.

27. Houts PS, Doak CC, Doak LG, Loscalzo MJ. The role of pictures in improving health communication: A review of research on attention, comprehension, recall, and adherence. Patient Educ Couns. 2006;61(2):173-190.

28. Krausch-Hofmann S, De Almeida Mello J, Declerck D, Declercq A, De Lepeleire J, Tran TD, et al. The oral health-related section of the interRAl: Evaluation of test content validity by expert rating and assessment of potential reasons for inaccurate assessments based on focus group discussions with caregivers. Gerodontology. 2019; doi: 10.1111/ger.12421.

29. Mehl AE, Ellingsen OG, Kjeksrud J, Willumsen T. Oral healthcare education of future nursing personnel and auxiliary nurses. Gerodontology. 2016;33(2):233-239.

30. Catteau C, Piaton S, Nicolas E, Hennequin M, Lassauzay C. Assessment of the oral health knowledge of healthcare providers in geriatric nursing homes: additional training needs required. Gerodontology. 2016;33(1):11-19. 


\section{Figures}

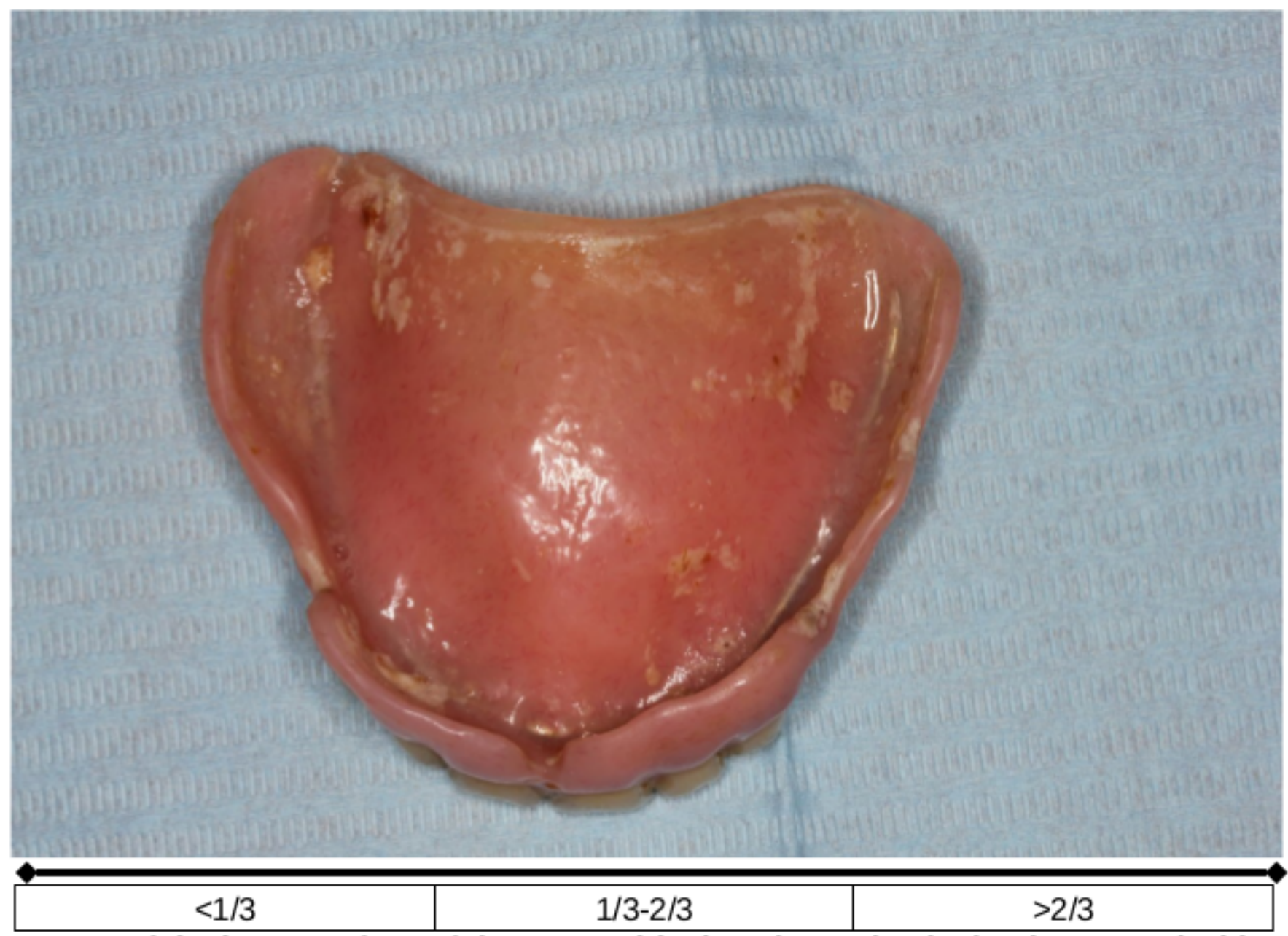

Part of the inner surface of the removable dental prosthesis that is covered with with plaque/tartar

Figure 1

Example of a photograph on denture hygiene and of the scale that was applied 


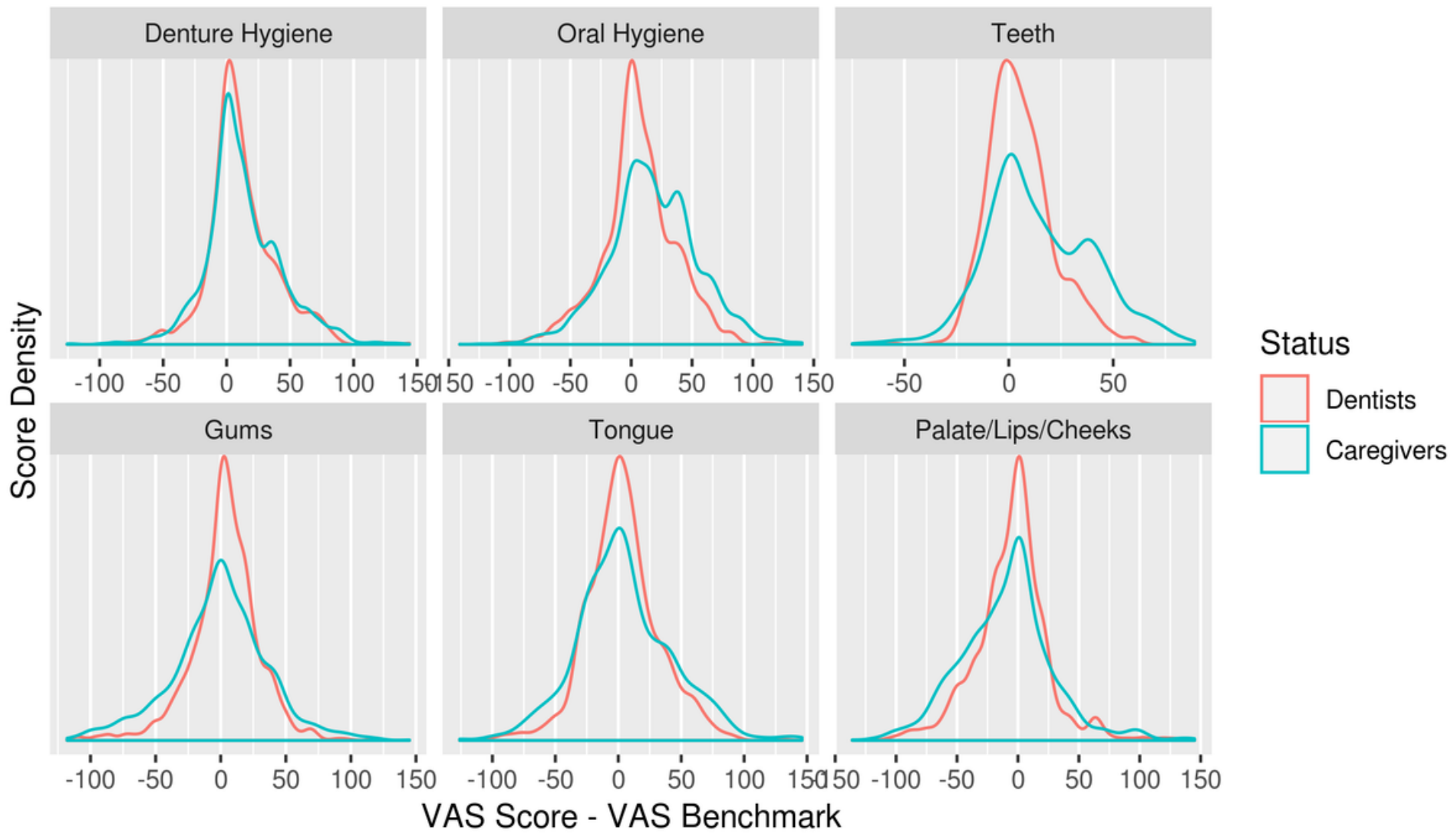

Figure 2

Density plots to illustrate distances from the benchmark scores for dentists and caregivers

\section{Supplementary Files}

This is a list of supplementary files associated with this preprint. Click to download.

- Dataset.xlsx 